\title{
D. Rasch und D. Schott, Mathematische Statistik für Mathematiker, Natur- und Ingenieurwissenschaftler
}

\section{Wiley-VCH, Weinheim, 2015, 648 pp., €79,} ISBN 978-3-527-33884-9

\author{
Walter Krämer ${ }^{1}$
}

An eternal challenge for authors of statistics textbooks is to establish a credible relationship between data $=$ the real world and the abstract concepts from which the mathematical theory of statistics evolves. The present book does this better than most. Its presumed audience are graduate students (with a good knowledge of probability) in natural sciences, engineering, but also mathematics. For the latter subgroup, the authors include proofs of all theorems and choose a very general approach which starts with the concepts of sufficiency and information. Also, before going into details of point estimation and testing there is a brief introduction into abstract statistical decision theory and its role in mathematical statistics. Among the remaining chapters, the ones on point estimation and testing are standard, but-possibly due to the professional interests of the authors - also include material such as sequential testing which is not easily found in other textbooks of this type. Similarly, the chapters on linear models, analysis of variance, regression and design of experiments somehow mirror the authors' research interests and do not claim to cover the whole universe of modern mathematical statistics. But this is anyway impossible in a textbook for students such as this.

Walter Krämer

walterk@statistik.tu-dortmund.de

1 Fakultät Statistik, Technische Universität, Dortmund, Germany 